Article

\title{
Comparative Gate-to-Gate Life Cycle Assessment for the Alkali and Acid Pre-Treatment Step in the Chemical Recycling of Waste Cotton
}

\author{
Lucas Rosson * and Nolene Byrne \\ Institute for Frontier Materials, Deakin University, 75 Pigdons Road, Waurn Ponds VIC 3216, Australia; \\ nolene.byrne@deakin.edu.au \\ * Correspondence: lrosson@deakin.edu.au
}

Received: 17 September 2020; Accepted: 14 October 2020; Published: 17 October 2020

\begin{abstract}
The development of textile recycling solutions is an area of intense research and commercialization. Chemical recycling solutions are becoming increasingly popular due to their ability to separate complex blends and retain or improve the value of the original fiber. The chemical recycling of cotton requires a pre-treatment step to reduce the degree of polymerization (DP). The DP can be reduced in a variety of ways, and here, the environmental footprints of two different pre-treatment approaches are examined using life cycle assessment (LCA); sodium hydroxide pre-treatment and sulphuric acid pre-treatment. We find that the acid pre-treatment has a significantly lower environmental footprint across all impact categories calculated. This is attributed to the lower treatment times required and the lower material and energy requirements for the manufacture of chemicals. The results were normalized to show the most significant impact categories for each pre-treatment, and further environmental implications of the pre-treatments are discussed. The findings will aid academia and industry in implementing the most environmentally benign processes in chemical cotton recycling.
\end{abstract}

Keywords: comparative life-cycle assessment; green chemistry; textile waste; cellulose pre-treatment; textile dyes

\section{Introduction}

To address the textile waste problem and a future potential shortage of cotton, the upcycling of textile waste is a necessity. Cotton fibers comprise a significant share of the global textile market [1], however, due to shortages in arable land coupled with the growing population, current cotton fiber manufacturing cannot sustain future demand [2,3]. The fast-fashion phenomenon, leading to a faster turn-over in garment styles and a growing middle-class population in need of cotton garments, is also contributing to this predicament [4]. In order to satisfy future demand and to aid the transition of the textile industry to a circular economy model it has been identified that renewable manufactured fibers will play a significant role [5]. Cotton fibers can be recycled mechanically or chemically, the former leads to shorter staple fiber lengths that in-turn impede yarn strengths and mechanical properties of garments [6]. Chemical recycling involves the dissolution and subsequent regeneration of cotton fibers. Once regenerated they are referred to as regenerated cellulose fibers (RCF) or man-made cellulose fibers. Commercial RCF exist, however, certain aspects of the processes used to create these fibers involve high energy input and the use of hazardous substances. The most commonly available commercial RCF is viscose-produced fibers. Production of viscose fibers involves cellulose derivation using carbon disulfide $\left(\mathrm{CS}_{2}\right)$, a substance known to be toxic, having detrimental effects on workers [7] and the environment [8]. This is followed by dissolution in caustic soda and regeneration in a sulphuric 
acid bath [9]. The use of corrosive chemicals and the toxicity of $\mathrm{CS}_{2}$ create inherent dangers to the environment. Tencel ${ }^{\mathrm{TM}}$ Lyocell fibers are growing in popularity and this process is considered to be more environmentally benign. Here the cellulose is dissolved in N-methyl-morpholine-N-oxide (NMMO) and coagulated in water. The Lyocell process requires significant energy in the form of heat, and involves the risk of dangerous exothermic degradation reactions [10]. Both viscose and Lyocell produced fibers use dissolving grade wood pulp as the cellulose source which itself has negative environmental side effects such as deforestation along with the harsh chemicals used in the wood pulp refining process [11-13].

Alternatives to using wood pulp for regenerated textile fibers include other cellulose sources such as orange peel [14], microbial cellulose [15] and cotton [16] which can be in the form of cotton linters and waste textile product $[17,18]$. Recently developed by our team is a technology for recycling waste cotton garments into RCF. Our process is reported in detail in a previous paper [18]. A critical step in the conversion of waste cotton textile into an RCF is the reduction in the degree of polymerization of the waste cotton, since cotton fabric typically has a DP of 2000-3000 compared with wood pulp which has a DP around 750 [19]. Reduction of DP can be achieved via a variety of methods however alkali treatment with sodium hydroxide and acid treatment with sulphuric acid are two of the most frequently occurring methods $[20,21]$. These chemicals have been selected as the two most promising approaches for pre-treatment of waste cotton $[16,22,23]$. To drive research and industry towards environmentally benign cotton waste recycling practices it is necessary to characterize and evaluate the environmental impact of the pre-treatment step. To compare the pre-treatment methods, life cycle assessment methodology was employed. Life cycle assessment (LCA) is an indispensable tool in assessing the environmental impacts of products and processes [24,25]. LCA is a comprehensive methodology to assess and quantify the environmental impacts of a product, process or service from raw material extraction through to final stages, such as disposal or recycling of the product or the process constituents [26-28]. Life cycle assessment of an entire process can often be time consuming and resource-intense. Furthermore, comparative life cycle assessments of two similar processes can lead to unnecessary modelling of identical flows in each process. Gate-to-gate life cycle assessment can be used to avoid these problems and simplify the modelling. Here the environmental impacts of sodium hydroxide and sulphuric acid pre-treatment of cotton waste is examined using a gate-gate LCA method. This assessment method has limitations in not accounting for environmental impacts caused by the production and use of the waste cotton prior to pre-treatment, or the impacts associated with the use of the pre-treated material. However, these impacts are not required in order to draw a quantitative comparison between the two processes investigated here. The work was motivated by the need to understand the environmental impacts of the pre-treatment of cotton waste, in order for chemical cotton recycling to succeed in a circular economy (Figure 1).

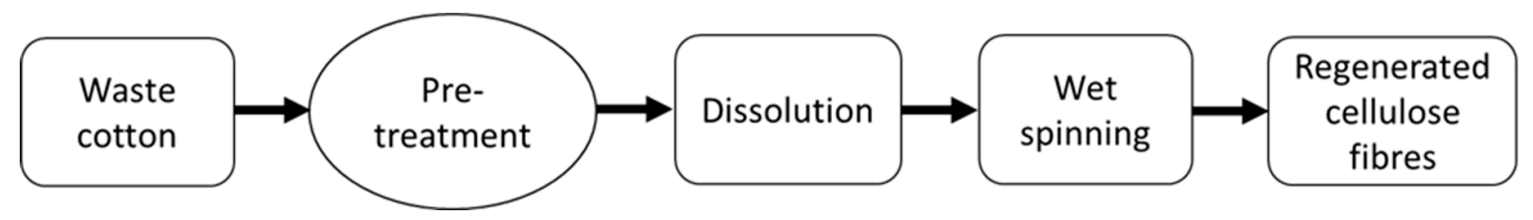

Figure 1. Flow chart for the chemical recycling of cotton where the pre-treatment step is achieved using either; $0.5 \mathrm{wt} \%$ sulphuric acid aqueous solution heated to $75^{\circ} \mathrm{C}$ for $1 \mathrm{~h}$ or $10 \mathrm{wt} \%$ sodium hydroxide aqueous solution heated to $90^{\circ} \mathrm{C}$ for $15 \mathrm{~h}$. 


\section{Materials and Methods}

\subsection{Pre-Treatment Process}

\subsubsection{Sodium Hydroxide Pre-Treatment}

In order to reduce the DP of cotton waste from approximately 2000 to approximately 1000 using sodium hydroxide, a long treatment duration and moderate temperatures were required. The cotton waste was shredded to a "chopped snippet" form with fiber lengths of approximately $0.2 \mathrm{~mm}$. The waste cotton was then added to a heated solution of $10 \mathrm{wt} \%$ sodium hydroxide and deionized water with a cotton concentration of $1 \mathrm{wt} \%$. The temperature of the solution was held at $90{ }^{\circ} \mathrm{C}$ for $15 \mathrm{~h}$ whilst being stirred at $250 \mathrm{rpm}$. The treated waste cotton was then filtered, washed, and dried, ready for dissolution and subsequent regeneration. Citric acid powder was added to the filtrate and wash water until the solution was $\mathrm{pH}$ neutral.

\subsubsection{Sulphuric Acid Pre-Treatment}

The sulphuric acid pre-treatment requires the same input cotton material in the form of chopped snippets. The sulphuric acid pre-treatment required a significantly reduced treatment duration compared to the sodium hydroxide method. The chopped snippets were added to a heated solution of $0.5 \mathrm{wt} \%$ sulphuric acid and deionized water with a cotton concentration of $1 \mathrm{wt} \%$. The temperature of the sulphuric acid-deionized water solution was held at $75^{\circ} \mathrm{C}$ for $1 \mathrm{~h}$ and was also stirred at $250 \mathrm{rpm}$. The sulphuric acid pre-treated cotton was filtered, washed, and dried in an identical manner to the sodium hydroxide pre-treated cotton. To neutralize the sulphuric acid filtrate and wash-water, sodium carbonate powder was added until a neutral $\mathrm{pH}$ was observed.

\subsection{Goal Definition}

The goal of this study was to assess the difference in environmental impacts caused by two methods for lowering the Degree of Polymerization (DP) of cotton waste. These methods are referred to as "pre-treatments" throughout this paper. Both pre-treatments involved heating cotton waste in aqueous solutions and are described in detail above. Fulfilling the goal of assessing the impacts of these processes aims to inform on the use of environmentally sound techniques during textile recycling.

\subsection{Scope Definition}

The scope was defined as gate-to-gate for the pre-treatment process. The scope of the LCA conducted in this paper included only the pre-treatment process, which involves the reduction of the DP of cotton waste to approximately 1000DP units. The study specifically focused on the environmental issues caused by the different treatment parameters; pre-treatment chemical, treatment energy, and neutralizing chemical. The life cycle assessment focuses on the pre-treatment step and considers this as the system boundary, excluding other material flows outside the boundary, such as the source of the waste cotton and the fate of the pre-treated cotton waste.

\subsection{System Boundaries}

The pre-treatment step is one of many steps involved in producing regenerated cellulosic fibers from cotton waste. The studied system included the electricity used for heating, the deionized water used for treatment and washing, the production and transport of treatment chemicals, and the production of neutralizing chemicals. The treatment of the wastewater was excluded as after neutralization, this was assumed to be identical for both processes. The system boundary can be seen in Figure 2 below. 


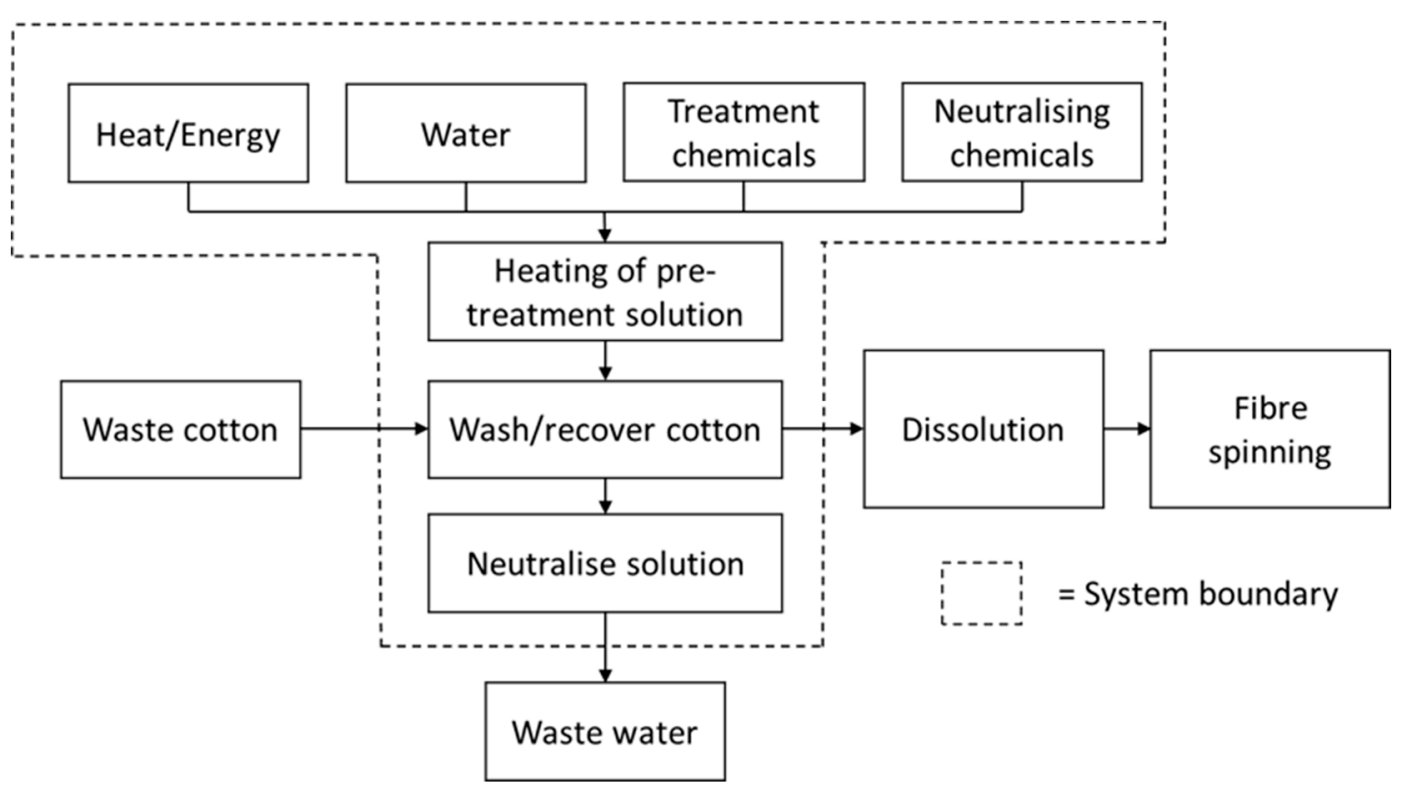

Figure 2. System boundary for pre-treatment step in chemical textile recycling.

\subsection{Functional Unit}

The functional unit was "the pre-treatment of $10 \mathrm{~g}$ of cotton waste". This represents the true scale of pre-treatments performed in the laboratory and therefore accurate values for resources and energy were known. For this unit, all inputs to the system were calculated, such as amount of treatment and neutralizing chemical required, the amount of water required, and the amount of energy required to heat the solution.

\subsection{Life-Cycle Inventory}

Data collection for the study involved foreground data such as the mass of deionized water and chemicals used, the estimated electrical energy used, and the estimated transport distances of the pre-treatment chemicals. This data was collected and estimated based on work completed in our laboratory. The background data was supplied by the Ecoinvent database in SimaPro 9.0.0.48 (PRÉ Consultants, Amersfoort, The Netherlands). The flows included in the inventory were; the production of deionized water for treatment and washing, the production and transportation of the pre-treatment chemicals, the production and distribution of electricity used to heat the solution, the production of neutralizing agents. In the Electronic Supplementary Information Figure S1 provides a diagram of the flows for each pre-treatment and Section S2 gives a description for each flow accompanied by a detailed table.

For each of the given flows listed in S1, an inventory of outputs/emissions were collected from the software and are listed in Tables S3 and S4 in the ESI. For the "raw" inputs into the processes, the top $10 \%$ of mass was reported, which comprised approximately $99.9 \%$ of the raw mass inputs for each process. As minuscule masses of certain substances can cause disproportionately high environmental impacts, the inputs and emissions resulting in the three highest impact scores for each impact category were also reported in the LCI. All emissions and inputs of raw materials were not able to be reported due to the copyright of the data provided by Ecoinvent. S1-S4 in the ESI provide a comprehensive inventory relative to the scope and goal of this study.

Allocation in LCA involves deciding which flows to attribute to a product system, when those flows and the emissions involved are shared by other product systems [29]. The ISO standards for LCA suggest that allocation should be avoided where possible. The unit processes contained in the background data mostly did not require allocation. Sulphuric acid production was considered to be a by-product of the processing of ores and the appropriate proportion of emissions was attributed to this 
flow automatically by the software. Sodium carbonate production was considered by the database to be a "multi-output process" and the allocation used by the software was based on stoichiometric calculations. For citric acid production allocation at the point of substitution was the default allocation method used. No allocation was required for the final product system, as it was considered to be a single output system.

\subsection{Impact Assessment}

The choice of impact assessment method was guided by the "Best Practice Guide for Mid-Point Life Cycle Impact Assessment in Australia" [30]. The guide states that for most Australian LCA studies, the CML-IA method was well-suited for many impact categories. This is also the recommended impact assessment method for processes with a global supply chain. Assessing the environmental impacts was therefore achieved using the CML-IA baseline World 2000 method in SimaPro. This allowed the processes to be compared for 11 impact categories:

- Abiotic depletion of minerals (ADP)—-measured in kilograms of antimony equivalents $\left(\mathrm{kg} S \mathrm{Sb}_{-\mathrm{eq}}\right)$

- Abiotic depletion of fossil fuels (ADP-ff)—measured in megajoules (MJ)

- Global warming (GWP100a) - measured in kilograms of carbon dioxide equivalents $\left(\mathrm{kg} \mathrm{CO}_{2-\mathrm{eq}}\right)$

- Ozone layer depletion (ODP) - measured in kilograms of CFC-11 equivalents (kg CFC-11-eq)

- Human toxicity (HTP)—measured in kilograms of 1,4-dichlorobenzene equivalents (kg 1,4-DB-eq)

- Freshwater aquatic ecotoxicity (FAETP)-measured in kilograms of 1,4-dichlorobenzene equivalents (kg 1,4-DB-eq)

- Marine aquatic ecotoxicity (MAETP)—-measured in kilograms of 1,4-dichlorobenzene equivalents (kg 1,4-DB-eq)

- Terrestrial ecotoxicity (TETP)—measured in kilograms of 1,4-dichlorobenzene equivalents (kg 1,4-DB-eq)

- $\quad$ Photochemical oxidation (PCOP)—measured in kilograms of ethylene equivalents $\left(\mathrm{kg} \mathrm{C} \mathrm{C}_{2} \mathrm{H}_{4-\mathrm{eq}}\right)$

- Acidification (AP)—measured in kilograms of sulfur dioxide equivalents $\left(\mathrm{kg} \mathrm{SO}_{2 \text {-eq }}\right)$

- $\quad$ Eutrophication (EP)—measured in kilograms of phosphate equivalents $\left(\mathrm{kg} \mathrm{PO}_{4}{ }^{3-}{ }_{\text {-eq }}\right)$.

\section{Results and Discussion}

\subsection{Impact Assessment for Sodium Hydroxide Pre-Treatment}

The characterized impact results were obtained by calculating emission equivalents for each environmental impact category related to each substance used and emitted throughout the life cycle for each pre-treatment method. This was achieved using SimaPro and the associated CML IA baseline characterization factors. In total, 11 impact categories were assessed, and these were detailed in the methodology section.

The characterized results of the Life Cycle Impact Assessment revealed that for the alkali pre-treatment process, six out of the eleven impact categories were dominated by the electricity used for heating the solution; Global warming, human toxicity, freshwater aquatic ecotoxicity, marine aquatic ecotoxicity, acidification potential and eutrophication potential. The major contribution to each of the impact categories for the alkali pre-treatment method can be broadly broken into being attributed to the electricity required in the heat step, the production of the sodium hydroxide chemical, and the production of the citric acid-neutralizing chemical. These three process components were responsible for over $87 \%$ of the impact for all categories. Figure 3 details the percentage contribution of each component of the alkali pre-treatment method for each impact category. (For detailed characterized values of equivalent emissions for each component within the alkali process, see Table S5 in the ESI). 


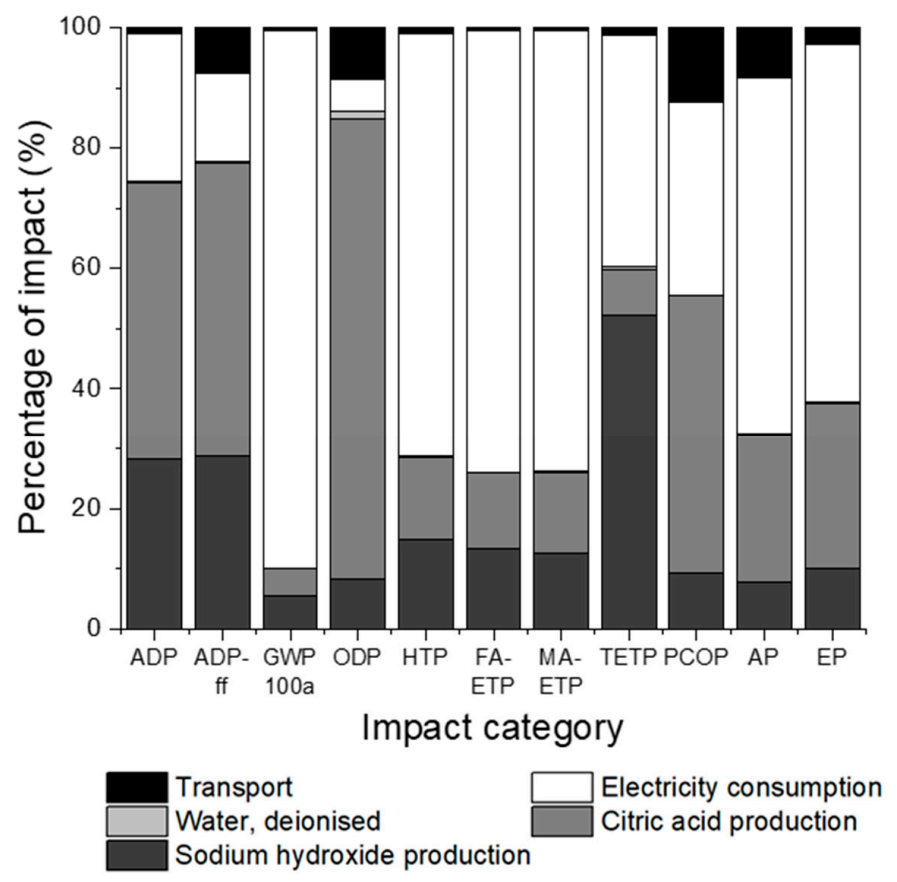

Figure 3. Percentage contribution of each process component to the characterized impact value for the alkali pre-treatment process.

For the impact categories to which electricity for heating contributed most, the percentage of the impact caused by the heating phase was calculated and the causes of these impacts are discussed here. The heating phase contributed $89 \%$ of the total $6.7 \mathrm{~kg} \mathrm{CO}_{2 \text {-eq }}$ impacting global warming (GWP) emitted during the alkali process. The large amount of $\mathrm{CO}_{2 \text {-eq }}$ here was caused mainly by the emission of carbon dioxide. The electricity for heating was sourced from the Victoria, Australia electricity grid, which generated over $82 \%$ of its power from the combustion of coal and natural gas in 2018 [31]. The combustion of these substances is known to emit carbon dioxide amongst other greenhouse gases (GHG) [32]. The alkali pre-treatment led to $1.11 \mathrm{~kg}$ 1,4-DB-eq emissions impacting human toxicity (HTP), of which heating electricity was responsible for more than $70 \%$. Thallium emissions to water were the main driver for this impact category. Thallium is a toxic substance whose emissions arise from the combustion of coal [33], explaining the high influence of the electricity used here on HTP. A similar portion of freshwater aquatic ecotoxicity (FAETP) and marine aquatic ecotoxicity (MAETP) was caused by the heating phase. Approximately $0.833 \mathrm{~kg}$ 1,4-DB-eq responsible for FAETP was emitted during the alkali pre-treatment, $73.5 \%$ of this was emitted during the heating phase. For MAETP, the characterized value was significantly higher than FAETP with $2690 \mathrm{~kg} 1,4-\mathrm{DB}_{\text {-eq }}$ being emitted throughout the process, $73.4 \%$ of which was caused by the heating phase. Beryllium emissions to water had the highest influence on both FAETP and MAETP. Beryllium, a lightweight metal, is used in a variety of applications, however, its emission to the environment often arises from coal-fired power generation [34], which justifies the high contribution from the heating phase in this process. The extreme characterized value for MAETP compared to FAETP is likely due to the manner in which beryllium and similar emitted compounds in a marine environment behave differently compared to a freshwater environment [35]. The total acidification (AP) characterized impact value was $0.00826 \mathrm{~kg} \mathrm{SO}_{2 \text {-eq }}, 59 \%$ of this was a result of the heating phase. Similarly, for eutrophication (EP), $59.5 \%$ of the total $0.00248 \mathrm{~kg} \mathrm{PO}_{4}{ }^{3-}$-eq emissions came from the heating phase. For both $\mathrm{AP}$ and $\mathrm{EP}$, the highest impact was caused by nitrogen oxide emissions to air. Again, the significant quantity of electricity sourced from coal-fired power generation was likely responsible for these emissions, as nitrogen oxide pollution is known to arise from coal combustion [36,37].

The environmental impact categories where electricity for heating did not constitute the majority of the impact were dominated by sodium hydroxide and citric acid production. These categories were 
abiotic depletion of minerals and fossil fuels (ADP and ADP-ff), photochemical oxidation (PCOP), ozone layer depletion (ODP) and terrestrial ecotoxicity (TETP). The production of citric acid leads to $46 \%$ of the abiotic depletion of minerals, with the total ADP value for the pre-treatment being $4.75 \times 10^{-6} \mathrm{~kg} \mathrm{Sb}$-eq. This impact was mainly caused by cadmium depletion. Cadmium is often found in zinc-containing ores [38] and zinc is known to be beneficial in the production of citric acid [39]. Therefore, this impact is likely caused by indirect cadmium depletion resulted from the mining of zinc ores for additives to the citric acid production process. Citric acid production also led to $48 \%$ of the total 6.32 MJ of abiotic depletion of fossil fuels. Citric acid production's ADP-ff impact came almost entirely from the use of anthracite or "hard coal". This variety of coal was likely used for energy during the citric acid production process. Out of the alkali pre-treatment components, citric acid production also had the highest photochemical oxidation impact, contributing $46 \%$ of the total $1.83 \times 10^{-4} \mathrm{~kg} \mathrm{C}_{2} \mathrm{H}_{4 \text {-eq }}$ emitted. The majority of these equivalent emissions came from sulfur dioxide emissions, which can be linked to the large amounts of sulphuric acid used in the product recovery phase of citric acid production [40]. The total ozone layer depletion impact was $4.67 \times 10^{-8} \mathrm{~kg}$ CFC-11-eq with $76 \%$ of this impact arising from citric acid production. The main contributing substance, carbon tetrachloride (tetra chloromethane, CFC-10) is banned or limited under the Montreal protocol [41]. The majority of citric acid was modelled to be manufactured in developing regions such as Mexico and Africa and these regions were later to adopt the protocol, which may be the reasoning behind the higher emissions of CFC-11 equivalents found here [42]. The production of sodium hydroxide caused over $52 \%$ of the $1,4-\mathrm{DB}_{-\mathrm{eq}}$ emissions related to terrestrial ecotoxicity, with the emissions contributing most to this being mercury emitted to air. More than half (55.1\%) of the sodium hydroxide production being modelled here was produced via the mercury cell technique, with mercury being the most concerning pollutant associated with the chlor-alkali industry [43]. This coupled with the large characterization factor associated with mercury emissions [30,44], played a large role in the dominating effect of sodium hydroxide production on the terrestrial ecotoxicity potential.

\subsection{Impact Assessment for Sulphuric Acid Pre-Treatment}

The total time required for the acid pre-treatment was significantly shorter than the alkali method and thus the electricity requirement associated with heating was lower. However, electricity for this pre-treatment remained the major contributor compared to the other process components across nine of the eleven impact categories. The heating phase in the acid pre-treatment contributed more than any other process phase for; global warming potential, freshwater aquatic ecotoxicity, marine aquatic ecotoxicity, human toxicity, terrestrial ecotoxicity, photochemical oxidation, acidification, eutrophication, and abiotic depletion of minerals. Almost all the total $0.491 \mathrm{~kg} \mathrm{CO}_{2-\mathrm{eq}}$ emissions in the acid process came from the heating electricity $(96 \%)$. The substance contributing most to global warming was carbon dioxide, and as the heating electricity phase was from the same source as in the alkali method, the source of $\mathrm{CO}_{2}$ emissions was the same. The heating phase made up over $91 \%$ of the 1,4-DB-eq emissions affecting both freshwater and marine aquatic ecotoxicity, whose total emission equivalents were $0.0528 \mathrm{~kg}$ and $169 \mathrm{~kg}$ 1,4-DB-eq, respectively. Beryllium emissions to water contributed most to these $1,4-\mathrm{DB}_{\text {-eq }}$ emissions, as was the case for the alkali process. The acid pre-treatment leads to $0.072 \mathrm{~kg}$ 1,4-DB-eq emissions impacting human toxicity, of this, approximately $86 \%$ came from the use of electricity for heating. This impact was dominated by the emissions of thallium to water. The main emissions impacting FAETP, MAETP and HTP likely arose from the combustion of coal for power generation, as was seen in the alkali method. The terrestrial ecotoxicity impact created by the acid method was $4.88 \times 10^{-4} \mathrm{~kg} 1,4-\mathrm{DB}_{\text {-eq }}$ and $77 \%$ of this arose from the heating phase. The substance with the highest contribution to this impact value was the emission of mercury. The combustion of coal has been labelled as one of the worst anthropogenic emission sources of mercury around the globe [45], which explains the high mercury emissions found in the heating electricity. For photochemical oxidation, a total of $9.97 \times 10^{-6} \mathrm{~kg} \mathrm{C}_{2} \mathrm{H}_{4-\text { eq }}$ were emitted, with the electricity for heating contributing $46 \%$ of this. Sulphur dioxide emitted in the sulphuric acid 
production had the highest individual contribution to this impact, however, the emissions of methane and carbon monoxide during the heating phase lead to the electricity phase contributing more to the impact overall. Nitrogen oxides emitted, likely from the combustion of coal as mentioned in the previous section, lead to the electricity for heating phase to contribute significantly to both acidification and eutrophication. A percentage of $74 \%$ of the $\mathrm{SO}_{2 \text {-eq }}$ affecting the acidification impact was due to the heating phase whilst $80 \%$ of the $\mathrm{PO}_{4}{ }^{3-}$-eq affecting eutrophication was attributed to heating. The abiotic depletion of minerals was $1.91 \times 10^{-7} \mathrm{~kg} \mathrm{Sb}$-eq in the acid pre-treatment and a significant proportion $(48 \%)$ arose in the electricity phase. Interestingly, the main contributor to this was the extraction of tellurium, a semi-metallic, and harmless element. This element is absorbed from soil by plants which leads to it being found in coal [46]. When coal is combusted, the tellurium is not recovered, leading to it being depleted. The dominance of the "electricity consumption" phase here indicated the lack of environmental impact caused by the other stages of the acid pre-treatment. The electricity consumption equated to $0.45 \mathrm{kWh}$ consumed from the local electricity grid, which is equivalent to running a domestic refrigerator for $2.5 \mathrm{~h}$ [47].

The two remaining impact categories where electricity for heating did not have the highest contribution were; abiotic depletion of fossil fuels and ozone layer depletion. For abiotic depletion of fossil fuels, acid pre-treatment resulted in $0.242 \mathrm{MJ}$ of depletion. Of this, $53 \%$ was caused by sodium carbonate production, mainly from the depletion of natural gas. Sodium carbonate production is known to be energy-intensive due to the high temperatures required [48] with natural gas a known source of energy in the sodium carbonate production process [49]. Over 50\% of the ozone layer depletion in the acid pre-treatment was a result of deionized water production. The database from which deionized water production data was collected stated that ion exchangers were used in the process. CFC-10 emissions which had the highest influence on ozone layer depletion are a known emission in the production of some ion exchange resins [50], and the emissions seen here likely arose from the production of materials for the ion exchangers. The contributions from each component of the acid process for each impact category are displayed in Figure 4. For ease of display and due to their small contribution, the two different transport components were amalgamated. Details of the characterized impacts associated with each component of the acid process can be found in Table S6 in the ESI.

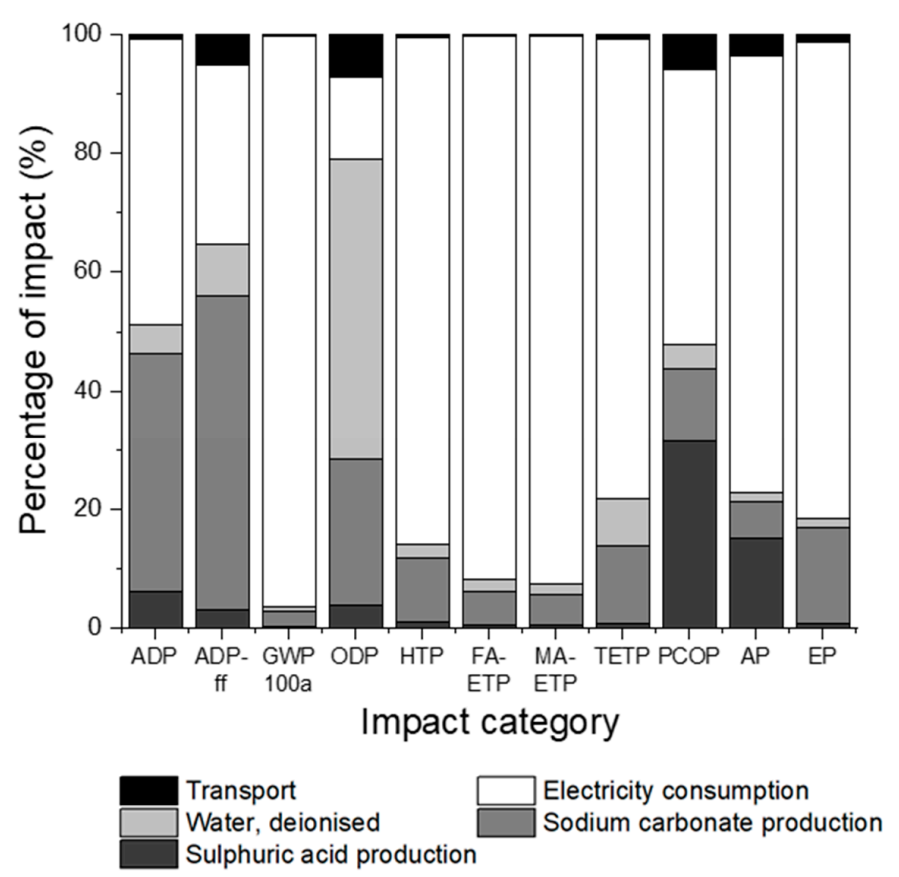

Figure 4. Percentage contribution of each process component to the characterized impact value for the sulphuric acid pre-treatment process. 


\subsection{Comparison of Pre-Treatment Methods}

Despite the environmental impacts of both pre-treatment methods being dominated by electricity use, in terms of characterized impact values, the alkali pre-treatment impact values were at least an order of magnitude higher than those caused by the acid pre-treatment for every impact category. A comparison of characterized impact values between the two different methods is shown in Table 1 . The impacts of the alkali method ranged from 13.6 times higher than that of the acid method for global warming potential to 33.1 times higher for ozone layer depletion. These substantial differences were mostly caused by the increased requirement of electricity in the alkali pre-treatment. Another contributing factor is likely the mass of the chemicals needed. The alkali process required 20 times more mass of treatment chemical and an estimated 5 times more neutralizing chemical. Due to these larger masses, the impacts of transporting the treatment chemical were higher in the alkali method, and more energy and raw materials were needed for manufacture per functional unit.

Table 1. Comparison of characterized impacts between sodium hydroxide and sulphuric acid pre-treatments for all CML environmental impact categories.

\begin{tabular}{|c|c|c|c|}
\hline Impact Category & Unit & $\begin{array}{c}\text { Sulphuric Acid Pre-Treated } \\
\text { Cotton Waste }\end{array}$ & $\begin{array}{c}\text { Sodium Hydroxide } \\
\text { Pre-Treated Cotton Waste }\end{array}$ \\
\hline Abiotic depletion & $\mathrm{kg} \mathrm{Sb}-\mathrm{eq}$ & $1.91 \times 10^{-7}$ & $4.75 \times 10^{-6}$ \\
\hline Abiotic depletion (fossil fuels) & MJ & $2.42 \times 10^{-1}$ & $6.32 \times 10^{0}$ \\
\hline Global warming (GWP100a) & $\mathrm{kg} \mathrm{CO}_{2-\mathrm{eq}}$ & $4.91 \times 10^{-1}$ & $6.70 \times 10^{0}$ \\
\hline Ozone layer depletion (ODP) & $\mathrm{kg}$ CFC-11 - eq & $1.41 \times 10^{-9}$ & $4.67 \times 10^{-8}$ \\
\hline Human toxicity & kg $1,4-\mathrm{DB}_{\text {-eq }}$ & $7.20 \times 10^{-2}$ & $1.11 \times 10^{0}$ \\
\hline Fresh water aquatic ecotox. & kg $1,4-\mathrm{DB}_{\text {-eq }}$ & $5.28 \times 10^{-2}$ & $8.33 \times 10^{-1}$ \\
\hline Marine aquatic ecotoxicity & $\mathrm{kg} 1,4-\mathrm{DB}_{\text {-eq }}$ & $1.69 \times 10^{2}$ & $2.69 \times 10^{3}$ \\
\hline Terrestrial ecotoxicity & $\mathrm{kg} 1,4-\mathrm{DB}_{\text {-eq }}$ & $4.88 \times 10^{-4}$ & $1.24 \times 10^{-2}$ \\
\hline Photochemical oxidation & $\mathrm{kg} \mathrm{C}_{2} \mathrm{H}_{4-\mathrm{eq}}$ & $9.97 \times 10^{-6}$ & $1.83 \times 10^{-4}$ \\
\hline Acidification & $\mathrm{kg} \mathrm{SO}_{2-\mathrm{eq}}$ & $5.21 \times 10^{-4}$ & $8.26 \times 10^{-3}$ \\
\hline Eutrophication & $\mathrm{kg} \mathrm{PO}_{4}{ }^{3-}-\mathrm{eq}$ & $1.45 \times 10^{-4}$ & $2.48 \times 10^{-3}$ \\
\hline
\end{tabular}

The nature of the production of the chemical also contributed to the environmental impact of each of the chemicals used here. In terms of impact per kilogram of pre-treatment chemical produced sulphuric acid production had a lower impact than sodium hydroxide production for all but two of the environmental impact categories; photochemical oxidation and acidification. For photochemical oxidation, sulphuric acid production had 3.7 times more impact than sodium hydroxide production. For acidification, sulphuric acid production's impact was 2.5 times higher. This was mainly caused by sulfur dioxide emissions from sulphuric acid production, a substance that has a large impact on both acidification and photochemical oxidation [30]. Per kilogram, the benefits of sulphuric acid production over sodium hydroxide production ranged from 3.6 times less impact in terms of ozone layer depletion to 84 times less in terms of terrestrial ecotoxicity. In terms of impact per mass of neutralizing agents used, the citric acid production included in the alkali pre-treatment resulted in a higher impact for all of the modelled impact categories compared to sodium carbonate production used in the acid pre-treatment. These differences found between the treatment and neutralizing chemicals used for each process reveal the influence chemical selection can have on the environmental impact of a process. The production parameters of chemicals can affect the environmental impact in a number of ways, including the energy used to manufacture the chemical, the raw materials used to create the chemical, and the waste and emissions involved therewith. A study on the gate-to-gate process energy for the manufacture of chemicals stated that sodium hydroxide production required a net energy use of 3.04 MJ per kilogram whilst sulphuric acid required $0.408 \mathrm{MJ}$ per $\mathrm{kg}$ [44]. The energy required to manufacture sulphuric acid was low due to the exothermic reactions involved allowing heat energy to be recovered and reused in the form of steam. The higher value for sodium hydroxide manufacture was a result of the process relying heavily on electricity. Using excess energy allows for the use of fossil-fuel energy to be replaced. The sodium hydroxide manufacturing process also has significant 
complexities involved with all three common methods of production (diaphragm, membrane and mercury) [51]. The diaphragm method uses asbestos which needs replacing after 3-4 months of use and results in sodium hydroxide of low quality. The membrane method is similar to the diaphragm method, however here the membrane consists of cellulosic material and produces high-quality sodium hydroxide. The drawbacks of the membrane method are the high brine quality requirements and the higher cost of the membrane. The mercury method results in high-quality sodium hydroxide production though it suffers from the use of hazardous mercury and the associated environmental cost. All methods have high electricity or thermal energy requirements [51,52]. The sodium hydroxide production mix in Ecoinvent database used here was modelled as $55.1 \%$ from the mercury cell method, $23.5 \%$ from the diaphragm cell method and $21.4 \%$ from the membrane cell method.

\subsection{Normalisation}

To compare the scores of impact categories against other categories, normalization of the characterization scores was undertaken. Normalization in LCA involves calculating a value for each impact category based on the modelled characterization value and the relevant normalization factor for that particular category. In this case, the normalization factors used were the CML-IA world 2000 normalization factors, which account for all emissions and equivalents related to each impact category. The characterized value is divided by the total amount of that emission, for example, total $\mathrm{CO}_{2-\text { eq }}$, for the world per year. Normalization allows for the environmental significance of each process to be compared across different impact categories, unlike in characterization impact assessment, which only allows for comparison of components within an impact category, or comparison of the same impact category for different products or processes.

Figures 5 and 6 show a comparison between the normalized impact values for the alkali and acid pre-treatment methods, respectively. The figures show that for both pre-treatment methods, similar impact categories are affected far more than other categories. That is, GWP100a, HTP, FAETP and MAETP are all significantly higher than the other impact categories. The normalized impact values of the alkali pre-treatment were far greater than those for the acid pre-treatment. This was expected, as the normalized impact value is scaled linearly from the characterized impact value. The reasoning for both processes showing similarities in terms of comparison across impact categories was likely caused by the electricity used for heating. Other common components for both processes such as transport and deionized water use had a small impact on the total values for most impact categories. Although the electricity used for heating was far less in quantity for the acid pre-treatment, this electricity consumption's impact in both processes, compared to other components, had a dominating effect.

\subsection{Process Improvement and Further Implications}

To highlight the influence that chemical choice has on environmental impact, and given the significant contribution the electricity for heating had here, the model was recalculated excluding the electricity used for heating in both processes. It is worth noting this would be a true scenario if theoretical net zero-emission energy production was used to generate the electricity. It is also important to mention that the electricity for heating was calculated from laboratory devices, and if industrial processes were used the energy requirements would likely decrease for both pre-treatment methods. The alkali pre-treatment method still had impact values far greater than the acid pre-treatment. In fact, by excluding heating electricity, the differences between the two methods became greater than the initial assessment which included electricity for heating. Differences ranged from the alkali process having 23.4 times greater impact for photochemical oxidation potential to 69.1 times greater impact for terrestrial ecotoxicity, compared to the acid pre-treatment. The characterized impacts of each component for each process with the electricity for heating excluded are supplied in Tables S7 and S8 in the ESI. These large differences were likely due mainly to the increased amount of energy required for the production of sodium hydroxide and citric acid compared to the other treatment and neutralizing chemicals used, and the larger mass of chemicals required to achieve the same desired effect. 


\section{Sodium hydroxide pre-treatment}

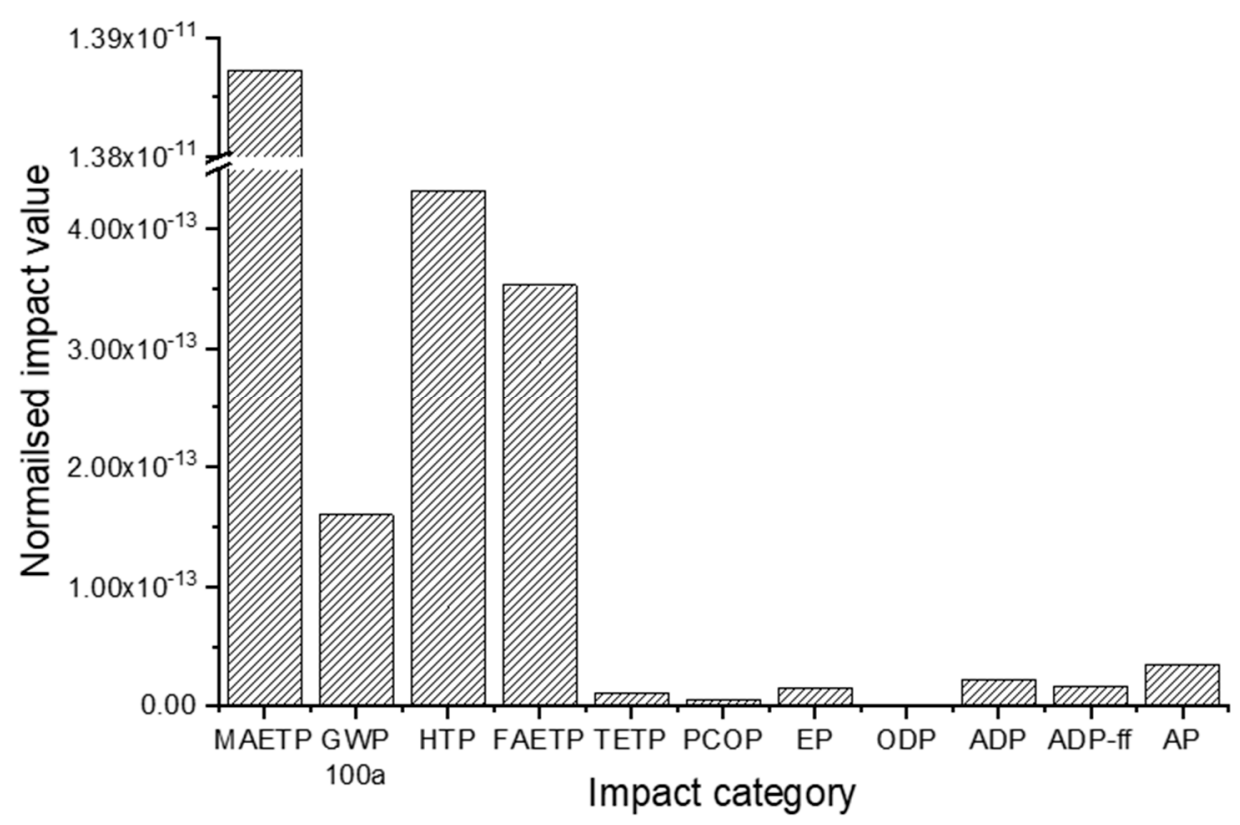

Figure 5. Normalized impact of sodium hydroxide process for all impact categories.

\section{Sulphuric acid pre-treatment}

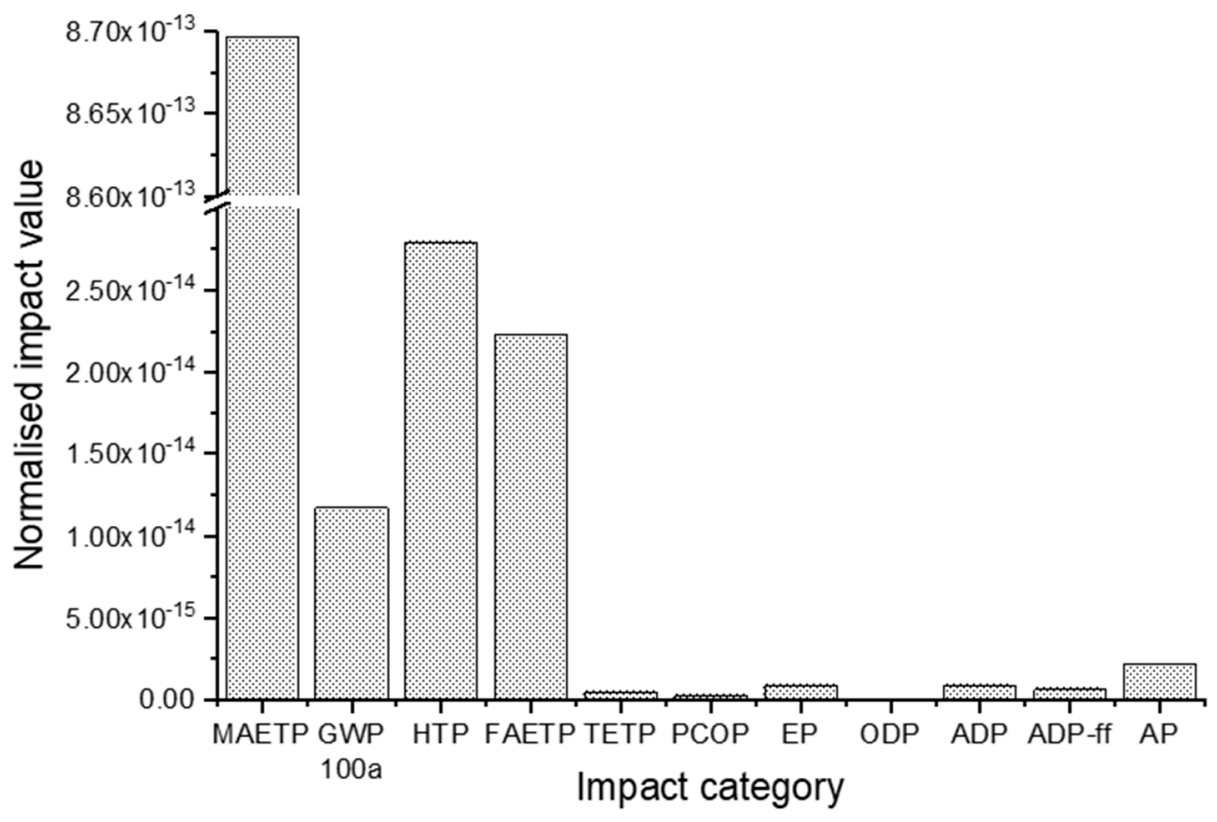

Figure 6. Normalized impact of sulphuric acid process for all impact categories.

We have so far demonstrated the ability of the sulphuric acid pre-treatment to environmentally out-perform the sodium hydroxide pre-treatment in terms of all assessed impact categories using life cycle assessment. However, the implications of employing this acid pre-treatment instead of the alkali counterpart may be further reaching than saving emissions in the pre-treatment of waste cotton for recycling. The acid pre-treatment allows for a significant amount of the dye to be retained in the fiber, and this dye has been shown to remain on the fiber through regeneration and production into fabrics $[16,18]$. The ability to retain dye in a chemically recycled fiber has the potential to displace the need to re-dye recycled fibers and fabrics. The textile industry is one of the world's worst polluters [11], and the most polluting process in the industry is the dyeing of textiles $[26,53,54]$. Enabling the recycling 
of not only textiles but also the dye contained on those textiles would allow for savings in water use, energy consumption, toxic chemical use, effluent discharge into waterways, and all the associated environmental impacts. The recycling of dyed textiles contains no compromise in the mechanical properties of the regenerated cellulose fibers, as can be seen in the results of our previous study [18]. Acid pre-treated RCF's have similar properties to RCF's whose source material was pre-treated via alkali techniques and these regenerated cellulose fibers have similar mechanical properties to commercial viscose fibers. Further to this, the use of sulphuric acid as a pre-treatment for waste cotton proved to be able to be regenerated with color and produce bright-colored garments [16] with good color fastness [55].

\section{Conclusions}

This paper demonstrates the ability of LCA software to be used as a screening tool not only during product and process development, but also during laboratory research. The results can guide researchers and engineers in creating processes that are quantitatively better for the environment and move towards generating processes which themselves enable a circular economy model. Here, a detailed gate to gate LCA was conducted comparing two alternative approaches for reducing the DP of waste cotton. It was found that the sulphuric acid approach had a significantly lower impact compared to the sodium hydroxide approach and therefore is selected as the preferred method for creating regenerated cellulose fibers from textile waste. The choice of the pre-treatment chemical influenced the amount of energy required for heating, and this significantly influenced environmental impacts. The neutralizing of wastewater also contributed to each pre-treatment process, and the impacts of the neutralizing chemicals were evaluated. The assessment also revealed the significance of chemical choice by modelling the pre-treatments with the exclusion of heating energy. The results consolidated the conclusion that the chemicals used in the sulphuric acid pre-treatment had lesser environmental impact compared to those used in the sodium hydroxide pre-treatment. Future studies may be interested in quantifying the environmental savings of retaining dye throughout the cotton chemical recycling process.

Supplementary Materials: The following are available online at http://www.mdpi.com/2071-1050/12/20/8613/s1, Figure S1: Diagram of flows for each pre-treatment process, Table S1: Table of process flows for each process and accompanying descriptions of flows, Table S2: Life cycle inventory for sodium hydroxide pre-treatment process, Table S3: Life cycle inventory for sulphuric acid pre-treatment process, Table S4: Impact category characterization values for sodium hydroxide process with the main contributing process component highlighted, Table S5: Impact category characterization values for sulphuric acid process with the main contributing process component highlighted, Table S6: Impact category characterization values for sodium hydroxide process excluding electricity for heating with the main contributing process component highlighted, Table S7: Impact category characterization values for sulphuric acid process excluding electricity for heating with the main contributing process component highlighted.

Author Contributions: Conceptualization, L.R. and N.B.; methodology, L.R. and N.B.; software, L.R.; validation, L.R. and N.B.; formal analysis, L.R.; investigation, L.R.; resources, N.B.; data curation, L.R.; writing-original draft preparation, L.R.; writing-review and editing, L.R. and N.B.; visualization, L.R.; supervision, N.B.; project administration, N.B.; funding acquisition, N.B. All authors have read and agreed to the published version of the manuscript.

Funding: This research received no external funding.

Acknowledgments: The authors would like to acknowledge the support of the Australian Government through an Australian Government Research Training Program Scholarship. The authors would also like to thank Mayuri Wijayasundara for her feedback and Timothy Grant from Lifecycles (Life Cycle Strategies Pty Ltd.) for training in life-cycle assessment and SimaPro software.

Conflicts of Interest: The authors declare no conflict of interest. 


\section{References}

1. The Fiber Year. The Fiber Year 2018. 2018. Available online: www.thefiberyear.com (accessed on 14 March 2019).

2. Haemmerle, F.M. The Cellulose Gap (the Future of Cellulose Fibres). In Lenzing-Nature Jeju Festival; Lenzinger Berichte: Jeju, Korea, 2011.

3. United Nations. World Population Prospects 2019; United Nations: New York, NY, USA, 2019.

4. Bick, R.; Halsey, E.; Ekenga, C.C. The global environmental injustice of fast fashion. Environ. Health 2018, 17, 92. [CrossRef]

5. The Fiber Year Consulting. The Fiber Year 2019 World Survey on Textiles and Nonwovens; The Fiber Year GmbH: Speicher, Switzerland, 2019.

6. Wanassi, B.; Azzouz, B.; Hassen, M.B. Value-added waste cotton yarn: Optimization of recycling process and spinning of reclaimed fibers. Ind. Crops Prod. 2016, 87, 27-32. [CrossRef]

7. Nurminen, M.; Hernberg, S. Effects of intervention on the cardiovascular mortality of workers exposed to carbon disulphide: A 15 year follow up. Br. J. Ind. Med. 1985, 42, 32. [CrossRef] [PubMed]

8. Enneking, J.C. Control of carbon disulfide emissions from viscose processes. Environ. Prog. 2002, 21, 169-174. [CrossRef]

9. Ma, Y.; Hummel, M.; Kontro, I.; Sixta, H. High performance man-made cellulosic fibres from recycled newsprint. Green Chem. 2018, 20, 160-169. [CrossRef]

10. White, P. Lyocell: The Production Process and Market Development. In Regenerated Cellulose Fibres; Woodings, C., Ed.; Woodhead Publishing: Cambridge, UK, 2001.

11. Common Objective. Mapping the Global Fashion Industry; Common Objective Ethical Fashion Group Ltd.: London, UK, 2018.

12. Ma, Y.; Hummel, M.M.; Määttänen, M.; Särkilahti, A.; Harlin, A.; Sixta, H. Upcycling of waste paper and cardboard to textiles. Green Chem. 2016, 18, 858-866. [CrossRef]

13. Batalha, L.A.; Colodette, J.L.; Gomide, J.L.; Barbosa, L.C.; Maltha, C.R.; Gomes, F.J. Dissolving Pulp Production from Bamboo. BioResources 2012, 7, 640-651.

14. Bicu, I.; Mustata, F. Cellulose extraction from orange peel using sulfite digestion reagents. Bioresour. Technol. 2011, 102, 10013-10019. [CrossRef]

15. Gao, Q.; Shen, X.; Lu, X. Regenerated bacterial cellulose fibers prepared by the $\mathrm{NMMO} \cdot \mathrm{H}_{2} \mathrm{O}$ process. Carbohydr. Polym. 2011, 83, 1253-1256. [CrossRef]

16. Haslinger, S.; Wang, Y.; Rissanen, M.; Lossa, M.B.; Tanttu, M.; Ilen, E.; Määttänen, M.; Harlin, A.; Hummel, M.; Sixta, H. Recycling of vat and reactive dyed textile waste to new colored man-made cellulose fibers. Green Chem. 2019, 21, 5598-5610. [CrossRef]

17. Shen, L.; Worrell, E.; Patel, M.K. Environmental impact assessment of man-made cellulose fibres. Resour. Conserv. Recycl. 2010, 55, 260-274. [CrossRef]

18. Ma, Y.; Rosson, L.; Wang, X.; Byrne, N. Upcycling of waste textiles into regenerated cellulose fibres: Impact of pretreatments. J. Text. Inst. 2019, 111, 630-638. [CrossRef]

19. Palme, A.; Theliander, H.; Brelid, H. Acid hydrolysis of cellulosic fibres: Comparison of bleached kraft pulp, dissolving pulps and cotton textile cellulose. Carbohydr. Polym. 2016, 136, 1281-1287. [CrossRef]

20. Bali, G.; Meng, X.; Deneff, J.I.; Sun, Q.; Ragauskas, A.J. The Effect of Alkaline Pretreatment Methods on Cellulose Structure and Accessibility. ChemSusChem 2015, 8, 275-279. [CrossRef]

21. Trache, D.; Hussin, M.H.; Haafiz, M.M.; Thakur, V.K. Recent progress in cellulose nanocrystals: Sources and production. Nanoscale 2017, 9, 1763-1786. [CrossRef]

22. Ma, Y.; Zeng, B.; Wang, X.; Byrne, N. Circular Textiles: Closed Loop Fiber to Fiber Wet Spun Process for Recycling Cotton from Denim. ACS Sustain. Chem. Eng. 2019, 7, 11937-11943. [CrossRef]

23. Asaadi, S.; Hummel, M.; Hellsten, S.; Härkäsalmi, T.; Ma, Y.; Michud, A.; Sixta, H. Renewable High-Performance Fibers from the Chemical Recycling of Cotton Waste Utilizing an Ionic Liquid. ChemSusChem 2016, 9, 3250-3258. [CrossRef] [PubMed]

24. International Organization for Standardization (ISO). Environmental Management-Life Cycle AssessmentPrinciples and Framework; ISO: Geneve, Switzerland, 1997.

25. International Organization for Standardization (ISO). Environmental management-Life Cycle AssessmentRequirements and Guidelines; ISO: Geneve, Switzerland, 2006. 
26. Esteve-Turrillas, F.A.; de la Guardia, M. Environmental impact of Recover cotton in textile industry. Resour. Conserv. Recycl. 2017, 116, 107-115. [CrossRef]

27. Goedkoop, M.; Oele, M.; Leijting, J.; Ponsioen, T.; Meijer, E. Introduction to LCA with SimaPro; Pré Consultants: Amersfoort, The Netherlands, 2016.

28. Yuan, Z.W.; Zhu, Y.N.; Shi, J.K.; Liu, X.; Huang, L. Life-cycle assessment of continuous pad-dyeing technology for cotton fabrics. Int. J. Life Cycle Assess. 2012, 18, 659-672. [CrossRef]

29. Adeniran, J.A.; Yusuf, R.O.; Adetoro, M.A. Life Cycle Engineering Case Study: Sulphuric Acid Production. J. Eng. Technol. 2017, 8, 2.

30. Renouf, M.A.; Grant, T.; Sevenster, M.; Logie, J.; Ridoutt, B.; Ximenes, F.; Bengtsson, J.; Cowie, A.; Lane, J. Best Practice Guide to Life Cycle Impact Assessment in Australia. Australian Life Cycle Assessment Society, 2018. Available online: www.alcas.asn.au (accessed on 1 October 2020).

31. Department of Energy and Environment. Australian Energy Statistics; Department of Energy and Environment: Canberra, Australia, 2019.

32. Agrawal, K.K.; Jain, S.; Jain, A.K.; Dahiya, S. Assessment of greenhouse gas emissions from coal and natural gas thermal power plants using life cycle approach. Int. J. Environ. Sci. Technol. 2014, 11, 1157-1164. [CrossRef]

33. Karbowska, B. Presence of thallium in the environment: Sources of contaminations, distribution and monitoring methods. Environ. Monit. Assess. 2016, 188, 640. [CrossRef]

34. Commonwealth of Australia. National Pollutant Inventory-Beryllium and Compounds; Department of Energy and Environment; Commonwealth of Australia: Canberra, Australia, 2018.

35. Tanveer, M.; Wang, L. Potential targets to reduce beryllium toxicity in plants: A review. Plant Physiol. Biochem. 2019, 139, 691-696. [CrossRef]

36. Yang, C.; Xia, M.; Dong, Z.; Wang, J.; Li, X. Analysis on Abatement Cost and Its Influencing Factors on Nitrogen Oxide Emissions from Power Plants in China. In Proceedings of the 2018 International Conference on Information Technology and Management Engineering (ICITME 2018), Beijing, China, 26-27 August 2018; Atlantis Press: Paris, France, 2018.

37. Rokni, E.; Panahi, A.; Ren, X.; Levendis, Y.A. Curtailing the generation of sulfur dioxide and nitrogen oxide emissions by blending and oxy-combustion of coals. Fuel 2016, 181, 772-784. [CrossRef]

38. Ross, R. Facts about Cadmium. 2018. Available online: https://www.livescience.com/37044-cadmium.html (accessed on 14 December 2019).

39. Tomlinson, N.; Campbell, J.J.R.; Trussell, P.C. The Influence of Zinc, Iron, Copper, And Manganese on The Production of Citric Acid by Aspergillus Niger. J. Bacteriol. 1950, 59, 217. [CrossRef] [PubMed]

40. Soccol, C.R.; Vandenberghe, L.P.S.; Rodrigues, C.; Pandey, A. New Perspectives for Citric Acid Production and Application. Food Technol. Biotechnol. 2006, 44, 141-149.

41. Fraser, P.J.; Dunse, B.L.; Manning, A.J.; Walsh, S.; Wang, R.H.; Krummel, P.B.; Steele, L.P.; Porter, L.W.; Allison, C.; O'Doherty, S.; et al. Australian carbon tetrachloride emissions in a global context. Environ. Chem. 2014, 11, 77-88. [CrossRef]

42. Max, B.; Salgado, J.M.; Rodríguez, N.; Cortés, S.; Converti, A.; Domínguez, J.M. Biotechnological production of citric acid. Braz. J. Microbiol. 2010, 41, 862-875. [CrossRef] [PubMed]

43. Crook, J.; Mousavi, A. The chlor-alkali process: A review of history and pollution. Environ. Forensics 2016, 17, 211-217. [CrossRef]

44. Kim, S.; Overcash, M. Energy in chemical manufacturing processes. J. Chem. Technol. Biotechnol. 2003, 78, 995-1005. [CrossRef]

45. Pyka, I.; Wierzchowski, K. Estimated mercury emissions from coal combustion in the households sector in Poland. J. Sustain. Min. 2016, 15, 66-72. [CrossRef]

46. Bullock, L.A.; Parnell, J.; Feldmann, J.; Armstrong, J.G.; Henn, A.S.; Mesko, M.F.; Mello, P.A.; Flores, E.M. Selenium and tellurium concentrations of Carboniferous British coals. Geol. J. 2019, 54, 1401-1412. [CrossRef]

47. Energy Use Calculator. Electricity Usage of a Refrigerator. 2020. Available online: http://energyusecalculator. com/electricity_refrigerator.htm (accessed on 10 December 2019).

48. Wu, Y.; Xie, H.; Liu, T.; Wang, Y.; Wang, F.; Gao, X.; Liang, B. Soda Ash Production with Low Energy Consumption Using Proton Cycled Membrane Electrolysis. Ind. Eng. Chem. Res. 2019, 58, 3450-3458. [CrossRef] 
49. Office of Air and Radiation. Technical Support Document for the Soda Ash Manufacturing Sector: Proposed Rule for Mandatory Reporting of Greenhouse Gases. U.S. Environmental Protection Agency: Washington, DC, USA, 2009. Available online: https://www.epa.gov/nscep (accessed on 14 March 2019).

50. Franzoni, E.; Volpi, L.; Bonoli, A. Applicability of Life Cycle Assessment methodology to conservation works in historical building: The case of cleaning. Energy Build. 2020, 214, 109844. [CrossRef]

51. Boustead, I. Eco-profiles for the European Plastics Industry: Sodium Hydroxide. PlasticsEurope 2005, 3, 13.

52. Garcia-Herrero, I.; Margallo, M.; Onandía, R.; Aldaco, R.; Irabien, A. Environmental challenges of the chlor-alkali production: Seeking answers from a life cycle approach. Sci. Total Environ. 2017, 580, 147-157. [CrossRef]

53. Kim, Y.; McCoy, L.T.; Lee, E.; Lee, H.; Saremi, R.; Feit, C.; Hardin, I.R.; Sharma, S.; Mani, S.; Minko, S. Environmentally sound textile dyeing technology with nanofibrillated cellulose. Green Chem. 2017, 19, 4031-4035. [CrossRef]

54. Sandin, G.; Peters, G.M. Environmental impact of textile reuse and recycling-A review. J. Clean. Prod. 2018, 184, 353-365. [CrossRef]

55. Nasri-Nasrabadi, B.; Wang, X.; Byrne, N. Perpetual colour: Accessing the colourfastness of regenerated cellulose fibres from coloured cotton waste. J. Text. Inst. 2020, 1-10. [CrossRef]

Publisher's Note: MDPI stays neutral with regard to jurisdictional claims in published maps and institutional affiliations.

(C) 2020 by the authors. Licensee MDPI, Basel, Switzerland. This article is an open access article distributed under the terms and conditions of the Creative Commons Attribution (CC BY) license (http://creativecommons.org/licenses/by/4.0/). 